\title{
A GCSS model intercomparison for a tropical squall line observed during toga- coare. II: Intercomparison of single- column models and a cloud-resolving model
}

Article

Published Version

Bechtold, P., Redelsperger, J.-L., Beau, I., Blackburn, M., Brinkop, S., Grandpeix, J.-Y., Grant, A., Gregory, D., Guichard, F., How, E. and loannidou, E. (2000) A GCSS model intercomparison for a tropical squall line observed during togacoare. II: Intercomparison of single-column models and a cloud-resolving model. Quarterly Journal of the Royal Meteorological Society, 126 (564). pp. 865-888. ISSN 1477870X doi: https://doi.org/10.1002/qj.49712656405 Available at https://centaur.reading.ac.uk/34979/

It is advisable to refer to the publisher's version if you intend to cite from the work. See Guidance on citing.

To link to this article DOI: http://dx.doi.org/10.1002/qj.49712656405

Publisher: Royal Meteorological Society

All outputs in CentAUR are protected by Intellectual Property Rights law, 
including copyright law. Copyright and IPR is retained by the creators or other copyright holders. Terms and conditions for use of this material are defined in the End User Agreement.

\section{www.reading.ac.uk/centaur}

\section{CentAUR}

Central Archive at the University of Reading

Reading's research outputs online 
A GCSS model intercomparison for a tropical squall line observed during TOGA-COARE. II: Intercomparison of single-column models and a cloud-resolving model

\author{
By P. BECHTOLD ${ }^{\text {* }}$, J.-L. REDELSPERGER ${ }^{2}$, I. BEAU ${ }^{2}$, M. BLACKBURN ${ }^{3}$, S. BRINKOP ${ }^{4}$, \\ J.-Y. GRANDPEIX ${ }^{5}$, A. GRANT ${ }^{6}$, D. GREGORY ${ }^{7}$, F. GUICHARD ${ }^{2}$, C. HOFF $^{2}$ and E. IOANNIDOU ${ }^{3}$ \\ ${ }^{1}$ Observatoire Midi-Pyrénées, France \\ ${ }^{2}$ Centre National de Recherche Météorologiques, France \\ ${ }^{3}$ University of Reading, $U K$ \\ ${ }^{4}$ Deutsche Zentrum für Luft- und Raumfahrt, Germany \\ ${ }^{5}$ Laboratoire de Météorologie Dynamique, France \\ ${ }^{6}$ Hadley Centre for Climate Prediction and Research, UK \\ ${ }^{7}$ European Centre for Medium-Range Weather Forecasts, UK
}

\title{
SUMMARY
}

This paper presents single-column model (SCM) simulations of a tropical squall-line case observed during the Coupled Ocean-Atmosphere Response Experiment of the Tropical Ocean/Global Atmosphere Programme. This case-study was part of an international model intercomparison project organized by Working Group 4 'Precipitating Convective Cloud Systems' of the GEWEX (Global Energy and Water-cycle EXperiment) Cloud System Study.

Eight SCM groups using different deep-convection parametrizations participated in this project. The SCMs were forced by temperature and moisture tendencies that had been computed from a reference cloud-resolving model (CRM) simulation using open boundary conditions. The comparison of the SCM results with the reference CRM simulation provided insight into the ability of current convection and cloud schemes to represent organized convection. The CRM results enabled a detailed evaluation of the SCMs in terms of the thermodynamic structure and the convective mass flux of the system, the latter being closely related to the surface convective precipitation. It is shown that the SCMs could reproduce reasonably well the time evolution of the surface convective and stratiform precipitation, the convective mass flux, and the thermodynamic structure of the squall-line system. The thermodynamic structure simulated by the SCMs depended on how the models partitioned the precipitation between convective and stratiform. However, structural differences persisted in the thermodynamic profiles simulated by the SCMs and the CRM. These differences could be attributed to the fact that the total mass flux used to compute the SCM forcing differed from the convective mass flux. The SCMs could not adequately represent these organized mesoscale circulations and the microphysical/radiative forcing associated with the stratiform region. This issue is generally known as the 'scale-interaction' problem that can only be properly addressed in fully three-dimensional simulations.

Sensitivity simulations run by several groups showed that the time evolution of the surface convective precipitation was considerably smoothed when the convective closure was based on convective available potential energy instead of moisture convergence. Finally, additional SCM simulations without using a convection parametrization indicated that the impact of a convection parametrization in forced SCM runs was more visible in the moisture profiles than in the temperature profiles because convective transport was particularly important in the moisture budget.

KEYWORDS: Convection parametrization Mass flux Single-column models

\section{INTRODUCTION}

In a recent critical survey paper Raymond (1997) stated 'There have been many observational studies of moist convection and many attempts to parameterize cumulus convection. However, there have been few of the former which have succeeded in aiding the latter, even though projects like GATE ${ }^{\dagger}$ were touted as serving this function'. The author continued 'I believe that the inability to make connections between these two important areas arises primarily from the lack of a well-defined and physically consistent conceptual framework for the parameterization of convection'.

While there still exists a lot of confusion about how to tackle atmospheric convection conceptually (although the mass-flux approach provides one possible mathematical

\footnotetext{
* Corresponding author: Laboratoire d'Aérologie, UMR UPS/CNRS 5560, Observatoire Midi-Pyrénées, 14 av Belin, 31400, Toulouse, France. e-mail: becp@aero.obs-mip.fr

$\dagger^{\dagger}$ GARP (Global Atmospheric Research Programme) Atlantic Tropical Experiment.
} 
framework) there is no doubt about the need to evaluate existing convection parametrizations further and to develop parametrizations that can be applied to variable horizontal resolutions. It has been shown (Slingo et al. 1994; Yano et al. 1996; Inness and Gregory 1998; Chao and Deng 1998) that in general-circulation models (GCMs) the mean climate of the tropics, its variability and cloud structure are strongly affected by the convection parametrization employed whereas, in operational weather forecast models and mesoscale models, the parametrization of deep convection is also critically important for simulating intense mesoscale precipitation events (Zhang and Fritsch 1988; Bélair et al. 1994; Sénési et al. 1996) and the development of extratropical cyclones (Davis et al. 1993). The current difficulties and possible future directions in the quantitative forecasting of mesoscale convective precipitation have been outlined by Fritsch et al. (1998). However, not only are model simulations sensitive to the deep convection parametrization, but also the deep-convection parametrization is itself sensitive to other parts of the model physics, like the formulation of the surface fluxes, turbulence, shallow convection, and radiation.

In the past, deep-convection parametrizations have been generally evaluated in single-column model (SCM) mode using observational data, and/or in a fully prognostic three-dimensional framework. Roughly speaking, convection schemes have been evaluated in SCM mode by semi-prognostic or prognostic tests. The semi-prognostic tests consist in retrieving the observed surface precipitation, the observed apparent convective heating/drying rates $Q_{1}, Q_{2}$, as well as the convective mass flux, given the observed temperature, moisture and vertical-velocity profiles (Arakawa and Schubert 1974; Bougeault 1985; Sun and Haines 1996). Emanuel (1997) criticized this 'traditional' evaluation procedure and proposed instead to make long-time integrations of SCMs with specified forcing, and to look at the prediction of thermodynamic quantities like the relative humidity. This procedure, as previously already employed by Betts and Miller (1986), can be regarded as a prognostic test; it has been used for the present first SCM intercomparison study.

Some authors have preferred evaluating convection schemes directly in a fully prognostic three-dimensional framework, especially for mesoscale applications (for example, Zhang and Fritsch 1988; Grell 1993; Wang and Seaman 1997). An alternative method consists in evaluating SCMs against output from cloud-resolving models (CRMs) (e.g. Xu and Arakawa 1992). The advantage of using CRM data is that quantities are available that cannot be measured with the required precision, like incloud temperature, in-cloud moisture and the area coverage of convective updraughts and downdraughts. However, Mapes (1997) pointed out that CRM results should be viewed with care because artificial boundary conditions, such as cyclic conditions, impose strong dynamical constraints that do not exist in unbounded domains- - a prominent example is the 'heating of the environment due to compensating subsidence' which, in bounded domains, can be considered as the equivalent of net latent-heat release and vertical eddy transport. Nevertheless, prognostic SCM tests, in spite of their shortcomings (no interaction with the environment through convergent flow at low levels and divergent outflow at high tropospheric levels), allow a detailed evaluation of convection schemes against observations and should, therefore, be considered as a necessary but not sufficient evaluation step for convection schemes. The two questions that then arise are: (i) how should we define SCM tests (forcing and evaluation) and (ii) how should we define appropriate observational data?

In this context, Working Group 4 'Precipitating Convective Cloud Systems' of the GEWEX (Global Energy and Water-cycle EXperiment) Cloud System Study (GCSS) 
(Moncrieff et al. 1997) has recently defined a strategy for studying precipitating convection and evaluating and developing convection parametrizations using data from field campaigns and data issued from CRMs. A first model intercomparison was organized in 1997 on two cases of the TOGA-COARE*, a seven-hour simulation of an intense squall line, and a six-day simulation of a succession of convective events. The squallline case has been described in Part I of this paper by Redelsperger et al. (2000; hereafter Part I); the results of the second case will be the subject of a forthcoming paper. As the squall-line event was defined as a short simulation it could be represented by both twodimensional (2D) and three-dimensional (3D) CRMs. The objectives of Part I were to compare the 2D and 3D CRM simulations for this event with existing observations, and to discuss to what extent CRM results are sensitive to technical and physical details, such as the definition of the computational domain size, and the formulation of the microphysics and the boundary conditions. Here, our objective is to present a first state-of-theart intercomparison of existing convection parametrizations and to evaluate them against a reference 3D CRM simulation that used a detailed microphysical parametrization and open boundary conditions. Unlike the philosophy suggested by Emanuel (1997), the simulations here are short, the focus being whether parametrizations are able to capture the various physical processes associated with organized convection rather than the equilibrium climate of convecting atmospheres.

The paper is organized as follows. In the next section we describe the SCMs that participated in this intercomparison, with special emphasis being given to the presentation of the deep-convection schemes employed. In the third section we present the method employed to force the SCMs, i.e. to introduce the 'large-scale' meteorological conditions. In sections 4 and 5 the results of the SCMs are illustrated and compared with the reference CRM simulation, and we further discuss some important points, such as the consequences on the results of the forcing method, the method of evaluation and some basic characteristics of convection schemes. A summary and outlook concludes this paper.

\section{DESCRIPTION OF THE SCMS}

\section{(a) Host models}

The eight different SCM groups that participated in this intercomparison project are listed in Table 1. With the exception of the LA (Laboratoire d'Aérologie) group that used a single-column version of a limited-area mesoscale model (the Meso-NH model), all other groups used single-column versions of a GCM. These groups were: CGAM (Centre for Global Atmospheric Modelling) using the UGAMP model; CNRM (Centre National de Recherche Météorologique) using the ARPEGE model; DLR (Deutsche Zentrum für Luft- und Raumfahrt) and KNMI (Koninklijk Nederlands Meteorologisch Instituut), both using versions of the ECHAM4 model; ECMWF (European Centre for Medium-Range Weather Forecasts) using the ECMWF model; LMD (Laboratoire de Météorologie Dynamique) using the LMDZ model; and HADLEY (Hadley Centre for Climate Prediction and Research) using the Unified Model (UM) of the UK Meteorological Office.

Table 1 also includes a description of the turbulence, radiation and microphysical schemes used in the SCMs. All models used either a first-order or 1.5-order turbulence scheme, together with a bulk surface scheme, to compute the turbulent fiuxes at the airsea interface. Most models used versions of the ECMWF radiation code. The models

\footnotetext{
* Tropical Ocean/Global Atmosphere Coupled Ocean-Atmosphere Response Experiment, a component of the World Climate Research Programme.
} 
TABLE 1. MAIN CHARACTERISTICS OF THE SINGLE-COLUMN MODELS USED FOR SIMULATING THE SQUALL LINE

\begin{tabular}{|c|c|c|c|c|c|c|}
\hline Group & Scientists & Host model & Turbulence scheme & Cloud scheme & Radiation scheme & Levels \\
\hline CGAM & $\begin{array}{l}\text { M. Blackbum } \\
\text { E. Ioannidou }\end{array}$ & $\begin{array}{l}\text { 1D UGAMP } \\
\text { GCM }\end{array}$ & $\begin{array}{l}\text { Louis (1979) } \\
\text { 1-order scheme }\end{array}$ & Diagnostic & Morcrette (1989) & 31 \\
\hline $\begin{array}{l}\text { CNRM- } \\
\text { GAME }\end{array}$ & I. Beau & $\begin{array}{l}\text { ID ARPEGE } \\
\text { GCM }\end{array}$ & $\begin{array}{l}\text { Louis (1979) } \\
\text { 1-order scheme }\end{array}$ & Diagnostic & Ritter and Geleyn (1992) & 44 \\
\hline DLR & S. Brinkop & $\begin{array}{l}\text { 1D ECHAM } \\
\text { GCM }\end{array}$ & $\begin{array}{l}\text { TKE } \\
1.5 \text {-order scheme }\end{array}$ & Prognostic & Morcrette (1989) & 19 \\
\hline ECMWF & $\begin{array}{l}\text { D. Gregory } \\
\text { F. Guichard }\end{array}$ & $\begin{array}{l}\text { 1D ECMWF } \\
\text { GCM }\end{array}$ & $\begin{array}{l}\text { Louis (1979) } \\
\text { l-order scheme }\end{array}$ & Prognostic & Morcrette (1989) & 31 \\
\hline KNMI & $\begin{array}{l}\text { P. Bechtold } \\
\text { E. van Meijgaard }\end{array}$ & $\begin{array}{l}\text { ID ECHAM } \\
\text { GCM }\end{array}$ & $\begin{array}{l}\text { Holtslag and Boville (1993) } \\
\text { 1-order scheme }\end{array}$ & Prognostic & Morcrette (1989) & 31 \\
\hline HADLEY & $\begin{array}{l}\text { A. Grant } \\
\text { R. Kershaw }\end{array}$ & $\underset{\text { GCM }}{\text { ID UM }}$ & $\begin{array}{l}\text { Richardson number } \\
\text { 1-order scheme }\end{array}$ & Diagnostic & Taylor et al. (1996) & 31 \\
\hline LA & P. Bechtold & $\begin{array}{l}\text { 1D MESO-NH } \\
\text { LAM }\end{array}$ & $\begin{array}{l}\text { Cuxart et al. }(2000) \\
1.5 \text {-order scheme }\end{array}$ & Prognostic & Morcrette (1989) & 41 \\
\hline LMD & J.-Y. Grandpeix & $\begin{array}{r}\text { ID LMDZ } \\
\text { GCM }\end{array}$ & $\begin{array}{l}\text { Blackadar (1979) } \\
\text { 1-order scheme }\end{array}$ & Diagnostic & Morcrette (1989) & 11 \\
\hline
\end{tabular}

The following notation is used in the third and fourth columns:

GCM-general-circulation model; LAM—limited-area model; TKE—turbulent kinetic energy.

used a variety of cloud schemes, both diagnostic and prognostic. All of the prognostic schemes had at least one additional variable for cloud water and provided a link between detrainment of cloud water from the convection scheme and the generation of stratiform cloud water. This is known to be an important contribution to the stratiform component of organized convection (for example, see Figs. 4 and 5 of Part I). Finally, the vertical resolution used in the models varied from 11 vertical levels in LMDZ to 44 levels in ARPEGE.

The objective of the present case-study was the evaluation of convection parametrizations. However, as the present case-study is defined as a short simulation ( 7 hours) of a violent maritime squall-line event with notable stratiform precipitation $(\approx 30 \%$ of total precipitation), we expected that the SCM results would be strongly sensitive not only to the convection parametrization and, maybe, to the time and space discretization applied, but also to a lesser extent to the microphysical (stratiform precipitation) scheme. Differences in the parametrization of turbulent and radiation fluxes were expected to be of minor importance.

\section{(b) Convection schemes}

A list of the convection parametrizations used by the different modelling groups is given in Table 2. Apart from the CGAM group that used a convective adjustment scheme (Betts and Miller 1993; Slingo et al. 1994), all the other SCM groups used bulk mass-flux parametrizations. In contrast to spectral schemes, such as the Arakawa and Schubert (1974) parametrization, that try to represent the spectrum of a whole cloud population, bulk mass-flux parametrizations consist of only one single convective updraught and downdraught couplet. The convection schemes utilized by the different modelling groups in a quasi-operational mode were as follows: CNRM used the scheme developed by Bougeault (1985), DLR and KNMI used the scheme developed by Tiedtke (1989) and modified by Nordeng (1994). The present ECMWF operational version is 
TABLE 2. CHARACTERISTICS OF THE DEEP-CONVECTION SCHEMES USED IN THE SINGLE-COLUMN MODELS

\begin{tabular}{|c|c|c|c|c|c|c|c|}
\hline Model & $\begin{array}{l}\text { Convection } \\
\text { scheme }\end{array}$ & Reference & Closure & Trigger & Downdraught & $\begin{array}{l}\text { Condensate } \\
\text { detrainment }\end{array}$ & $\begin{array}{l}\text { Calling interval } \\
\text { (min) }\end{array}$ \\
\hline CGAM & Adjustment & Betts and Miller (1993) & $\bar{A}$ & $\mathrm{CI}$ & Yes & No & 15 \\
\hline CNRM & Mass Flux & Bougeault (1985) & $\mathrm{MC}+\mathrm{QE}$ & $\mathrm{MC}+\mathrm{Cl}$ & No & No & 1 \\
\hline CNRM_c & Mass Flux & Bougeault (1985) & $\mathrm{CT}$ & $\mathrm{MC}+\mathrm{CI}$ & No & No & 1 \\
\hline DLR & Mass Flux & $\begin{array}{l}\text { Tiedtke (1989); } \\
\text { Nordeng (1994) }\end{array}$ & $\mathrm{CT}$ & $\mathrm{MC}+\mathrm{CI}$ & Yes & Yes & 40 \\
\hline ECMWF & Mass Flux & $\begin{array}{l}\text { Tiedtke (1989); } \\
\text { Gregory (1998) }\end{array}$ & $\mathrm{CT}$ & $\mathbf{C I}$ & Yes & Yes & 5 \\
\hline ECMWF_tk & Mass Flux & Tiedtke (1989) & MC & $\mathrm{MC}+\mathrm{CI}$ & Yes & Yes & 5 \\
\hline HADLEY & Mass Flux & Gregory and Rowntree (1990) & $\mathrm{CT}$ & $\mathrm{Cl}$ & Yes & No & 10 \\
\hline KNMI & Mass Flux & $\begin{array}{l}\text { Tiedtke (1989); } \\
\text { Nordeng (1994) }\end{array}$ & $\mathrm{CT}$ & $\mathrm{MC}+\mathrm{Cl}$ & Yes & Yes & 1 \\
\hline KNML_kf & Mass Flux & Kain and Fritsch (1993) & $\mathrm{CA}$ & $\mathrm{Cl}$ & Yes & Yes & 1 \\
\hline KNML_bm & Adjustment & Betts and Miller (1993) & A & $\mathrm{CI}$ & Yes & No & 1 \\
\hline KNMI_tk & Mass Flux & Tiedtke (1989) & MC & $\mathrm{MC}+\mathrm{Cl}$ & Yes & Yes & 1 \\
\hline LA & Mass Flux & $\begin{array}{l}\text { Bechtold (1997); } \\
\text { Kain and Fritsch (1993) }\end{array}$ & $\mathrm{CA}$ & $\mathrm{CI}$ & Yes & Yes & I \\
\hline LMD & Mass Flux & Emanuel (1991) & $\mathrm{CT}$ & CI & Yes & No & 10 \\
\hline
\end{tabular}

The following notation is used in the fourth and fifth columns:

A-adjustment; MC - moisture convergence; QE-quasi-equilibrium; CT-CAPE tendency; CA-CAPE adjustment; $\mathrm{CI}-$ convective instability; $\mathrm{MC}$-moisture convergence.

also based on the Tiedtke scheme but has been further developed by Gregory $e t$ al. (1998). Finally, LA, LMD and HADLEY parametrized deep convection with schemes developed by Bechtold (1997) and Kain and Fritsch (1993), by Emanuel (1991), and by Gregory and Rowntree (1990), respectively. In addition to their standard convection parametrizations, some modelling groups also tested other convection schemes, or tested modifications to their standard schemes (see group names with underscores in Table 2). In particular, the KNMI also tested the Kain and Fritsch (1993) scheme, the Betts and Miller (1993) scheme, as used by CGAM, as well as the original Tiedtke (1989) scheme.

Table 2 also provides a short description of some important characteristices of the convection parametrizations, such as: the type of convective closure (i.e. the condition that determines the intensity of convection); the trigger function (i.e. the required conditions to initiate convection); the representation of such downdraught effects as the melting of ice and the evaporation of precipitation; and the explicit detrainment of cloud water or ice. The convective closure used by the standard schemes was either based on moisture convergence, as used in the CNRM scheme, or on convective stability. However, most of the standard convection schemes in this intercomparison applied a stability-dependent closure based on the convective available potential energy (CAPE). This was done either by specifying the cloud-base mass flux as a function of the CAPE tendency or by relaxing the environment toward a convectively neutral state. In this latter sense, schemes based on a CAPE closure are similar to convective adjustment schemes. Furthermore, both mass-flux schemes based on a CAPE closure and convective adjustment schemes need to apply an adjustment time-scale $\tau$; this was set to one hour in most of the present schemes, but was $30 \mathrm{~min}$ in ECMWF and two hours in KNMI_bm. Concerning some other characteristics of convective parametrizations, we note that all schemes used a trigger based on convective instability and/or moisture convergence at 
the lifting condensation level, and that most schemes included the effects of convective downdraughts and the detrainment of condensate even if, in some schemes, condensate was assumed to evaporate immediately. Finally, we have listed in Table 2 the time intervals between the calls of the convection scheme by the host models; these were equal to the host models' time steps in the present study, and varied between 1 and 40 min. We wish to conclude the present section by calling the reader's attention to the fact that Table 2 is only intended to give a general overview and, moreover, that a deep convection scheme should be considered as an complete entity for which each technical and physical detail is important and might affect the quality of the scheme.

\section{EXPERIMENTAL DESIGN AND SCM FORCING}

The region of the squall line was characterized by mesoscale ascent representing strong adiabatic forcing on the scale of the 3D CRM domain, though accurate estimates of this forcing are not available from the observations (see Part I). The reference CRM (labelled RSI3D in Part I) was integrated with open lateral boundary conditions, allowing mean inflow and vertical motion to develop interactively with the intensifying convection. The time series of forcing of potential temperature $\theta$, and specific humidity $q_{\mathrm{v}}$ associated with the domain-averaged flow in the reference CRM simulation were computed and were used to force the SCMs. Note that this is only possible for CRM simulations with open lateral boundaries, otherwise the domain-averaged vertical motion vanishes and only unforced situations can be modelled.

Following Guichard et al. (1997), and using the anelastic continuity equation, the forcing tendencies can be written as

$$
\begin{aligned}
& \left.\frac{\partial \theta}{\partial t}\right|_{\mathrm{frc}}=-\frac{1}{\bar{\rho}} \frac{\partial}{\partial z}(\bar{\rho} \bar{w} \bar{\theta})-\overline{\frac{\partial}{\partial x} u \theta}-\overline{\frac{\partial}{\partial y} v \theta} \\
& \left.\frac{\partial q_{\mathrm{v}}}{\partial t}\right|_{\mathrm{frc}}=-\frac{1}{\bar{\rho}} \frac{\partial}{\partial z}\left(\bar{\rho} \bar{w} \bar{q}_{\mathrm{v}}\right)-\overline{\frac{\partial}{\partial x} u q_{\mathrm{v}}}-\overline{\frac{\partial}{\partial y} v q_{\mathrm{v}}},
\end{aligned}
$$

where overbars denote spatial averages over the whole CRM domain of $100 \times 125 \mathrm{~km}$ and time averages over 1 hour.

The SCMs were integrated forward in time starting with an initial vertical profile of $\theta, q_{\mathrm{v}}$ and horizontal wind components $u$ and $v$. The thermodynamic variables $\theta$ and $q_{\mathrm{v}}$ change in time following the equations

$$
\begin{aligned}
\frac{\partial \bar{\theta}}{\partial t} & =\left(C_{p} \bar{\Pi}\right)^{-1} Q_{1}+\left.\frac{\partial \theta}{\partial t}\right|_{\mathrm{frc}} \\
Q_{1} & =Q_{\mathrm{R}}+L_{\mathrm{v}}(\bar{c}-\bar{e})-C_{p} \bar{\Pi} \frac{1}{\bar{\rho}} \frac{\partial}{\partial z}\left(\bar{\rho} \overline{w^{\prime} \theta^{\prime}}\right) \\
\frac{\partial \bar{q}_{\mathrm{v}}}{\partial t} & =-L_{\mathrm{v}}^{-1} Q_{2}+\left.\frac{\partial q_{\mathrm{v}}}{\partial t}\right|_{\mathrm{frc}} \\
Q_{2} & =-L_{\mathrm{v}}\left[(\bar{c}-\bar{e})-\frac{1}{\bar{\rho}} \frac{\partial}{\partial z}\left(\bar{\rho} \overline{w^{\prime} q_{\mathrm{v}}^{\prime}}\right)\right],
\end{aligned}
$$

where the so-called apparent heat source $Q_{1}$ and moisture $\operatorname{sink} Q_{2}$ included the models' physical processes, such as radiation, water phase changes and convective and turbulent transport. $C_{p}$ and $L_{\mathrm{v}}$ denote the specific heat for dry air and the latent heat of condensation/sublimation, $\Pi=T / \theta$, and $\bar{c}-\bar{e}$ is the net condensation/sublimation. Throughout 


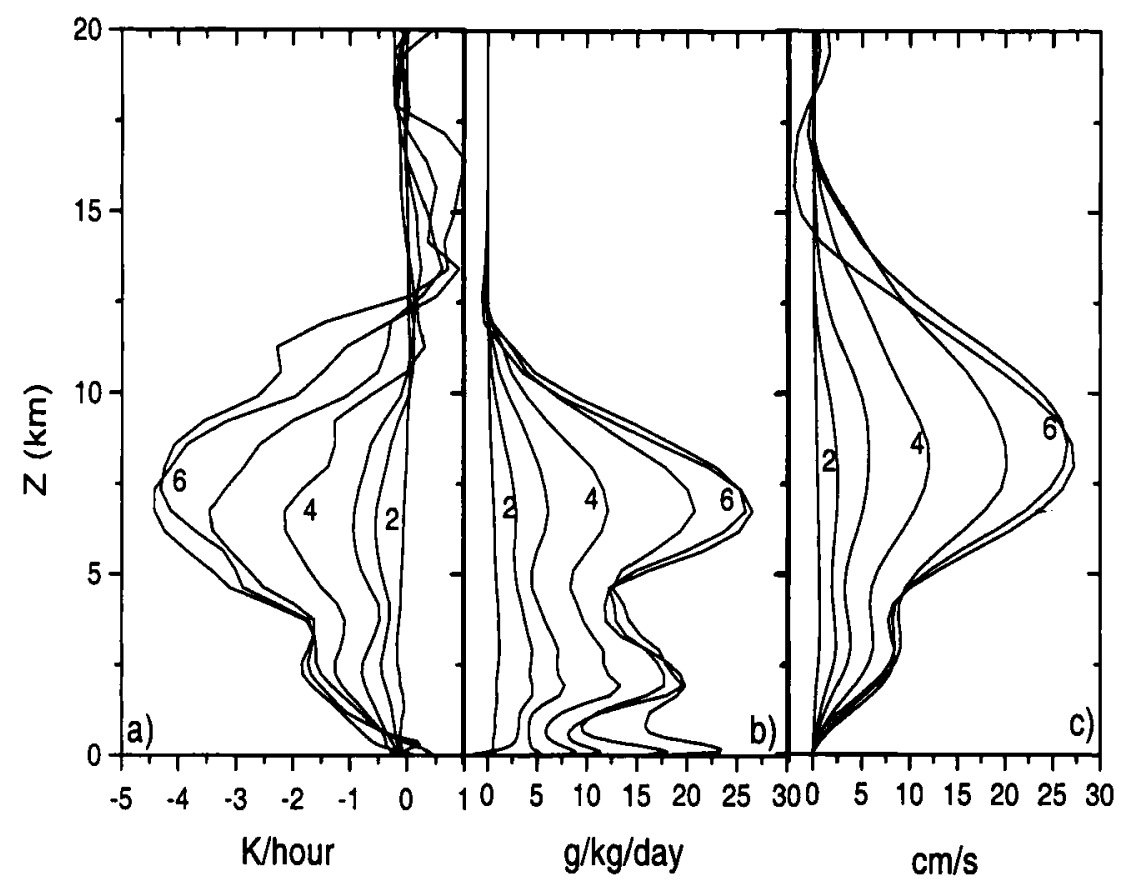

Figure 1. Hourly averaged forcing vertical profiles for each of the hours 1-7 (curves labelled for even hours only) of (a) the potential temperature, (b) the specific humidity and (c) the domain-averaged vertical velocity.

the rest of this paper we will make use of $Q_{1 \mathrm{C}}=Q_{1}-Q_{\mathrm{R}}$ instead of $Q_{1}, Q_{\mathrm{R}}$ being the radiative tendency term. The domain-average temporal tendencies (the left-hand sides of Eqs. (3) and (5)) are generally small so that $Q_{1 \mathrm{C}}$ and $Q_{2}$ are, to a first order approximation, equivalent to the corresponding forcing terms. Finally, concerning the horizontal wind components $u$ and $v$, we simply applied a Newtonian relaxation towards the initial profile $u_{0}$ with a time constant $\tau$ of 3 hours

$$
\left.\frac{\partial u}{\partial t}\right|_{\mathrm{frc}}=-\frac{\bar{u}-u_{0}}{\tau} \text { and }\left.\quad \frac{\partial v}{\partial t}\right|_{\mathrm{frc}}=-\frac{\bar{v}-v_{0}}{\tau} .
$$

No forcing was applied to other model variables, such as the microphysical variables.

The hourly averaged forcing profiles for $\theta$ and $q_{\mathrm{v}}$ over the seven-hour period of the CRM simulation are depicted in Fig. 1, together with the hourly averaged vertical velocity. Initially, the forcing tendencies were weak, but the system quickly developed between 3 and 6 hours and became quasi-stationary during the last hour, with maximum forcing tendencies attaining heating and moistening rates in the mid-troposphere of $110 \mathrm{~K} \mathrm{day}^{-1}$ and $25 \mathrm{~g} \mathrm{~kg}^{-1} \mathrm{day}^{-1}$, respectively. The maximum vertical velocities attained $25 \mathrm{~cm} \mathrm{~s}^{-1}$. As observed by Roux (1998), these profiles were characteristic for the TOGA-COARE region during perturbed conditions, especially the maximum in the heating profile between 7 and $8 \mathrm{~km}$ (Fig. 1(a)), the vertical-velocity maximum occurring between 8 and $9 \mathrm{~km}$, and the double-structured moistening profile (Fig. 1(c)). Recall that the vertical velocity is not used to force the dynamic model variables. However, some convection schemes need a 'large-scale' vertical velocity either to trigger convection or to specify the cloud-base mass flux. 
The tendency forcing that was used in this study ensured that all the SCMs were forced at each time step with the same tendency. However, tendency forcing is, in general, not equivalent to interactive vertical-velocity forcing, as applied in operational 3D runs of convection schemes. The resulting forced SCM simulations could be considered as 'off-line' tests of the response of the SCM parametrizations to the prescribed intense forcing. The simulations did not include the interactive feedback between forcing and convection that was present in the reference CRM and in high-resolution 3D GCM integrations. Thus the SCM simulations should have generally followed the CRM evolution (and also the observations, insofar as the CRM was able to reproduce the observed evolution faithfully).

\section{INTERCOMPARISON RESULTS}

The SCM simulations of the present squall-line case were conducted in a similar way to the reference CRM simulation (Part I). The SCMs were initialized with the sounding given in Table 3 of Part I, valid at 2000 UTC (0600 local time) for Honiara island located at $\left(160^{\circ} \mathrm{E}, 10^{\circ} \mathrm{S}\right)$, and were run for seven hours using the forcing profiles given in Fig. 1. The sea surface temperature and the surface pressure were kept constant with values of $301.3 \mathrm{~K}$ and $1006 \mathrm{hPa}$, respectively. A detailed description of the case and the protocol of the numerical experiments is also available on the GCSS World-WideWeb home page (http://www.cnrm.meteo.fr:8000/gcss/). The following discussion of the SCM results is intended to give a comprehensive overview on the basis of standard model output.

\section{(a) Time evolution}

The interesting feature of the present case was the occurrence of substantial convective and stratiform rain rates. Approximately $70 \%$ of the total surface rain rate was convective and 30\% stratiform. As reported by Short et al. (1997), this partitioning was typical for the TOGA-COARE region during disturbed conditions. Figure 2 illustrates the time evolution of the convective, stratiform and total rain rate, as simulated by the SCMs and the reference CRM (indicated by the thick line). Of course it is always somewhat arbitrary to distinguish between convective and stratiform precipitation in CRMs (see, for example, Alexander and Cotton (1998)) but the definition given in section 3 of Part I gives a reasonable estimate for squall lines. Several SCMs captured the partitioning between stratiform and convective precipitation quite well, producing peak convective rain rates of about $9 \mathrm{~cm}$ day $^{-1}$ at the end of the simulation. Some models (CNRM, ECMWF) exhibited some strong spin-up, or a rather spiky evolution, of the convective precipitation rates. The high spin-up in ECMWF was partly due to the short adjustment time-scale of $30 \mathrm{~min}$. However, initial spin-up is fundamentally different in CRMs and SCMs. Whereas in CRMs deep organized convection takes some time to build up (typically of the order of an hour), SCMs diagnose convection from a conditionally unstable sounding and can, therefore, initiate convection at $t=0$.

The results of DLR were a bit different to the others as the time step of $40 \mathrm{~min}$ used in this model was too large for the present quickly evolving $1 \mathrm{D}$ case study. Furthermore, we note that the spread in the model results concerning the total precipitation rates was much less (Fig. 2(c)); all models approximately reproduced the final total surface precipitation rate of $12 \mathrm{~cm} \mathrm{day}^{-1}$. The heating associated with the total surface precipitation rate of $12 \mathrm{~cm}$ day $^{-1}$ corresponded to $\approx 3500 \mathrm{~W} \mathrm{~m}^{-2}$ (or a $30 \mathrm{~K} \mathrm{day}^{-1}$ heating throughout the tropospheric column of $15 \mathrm{~km}$, using $\rho=0.65$ ) and approximately balanced the forcing (Fig. 1); this was much larger than typical or achievable 

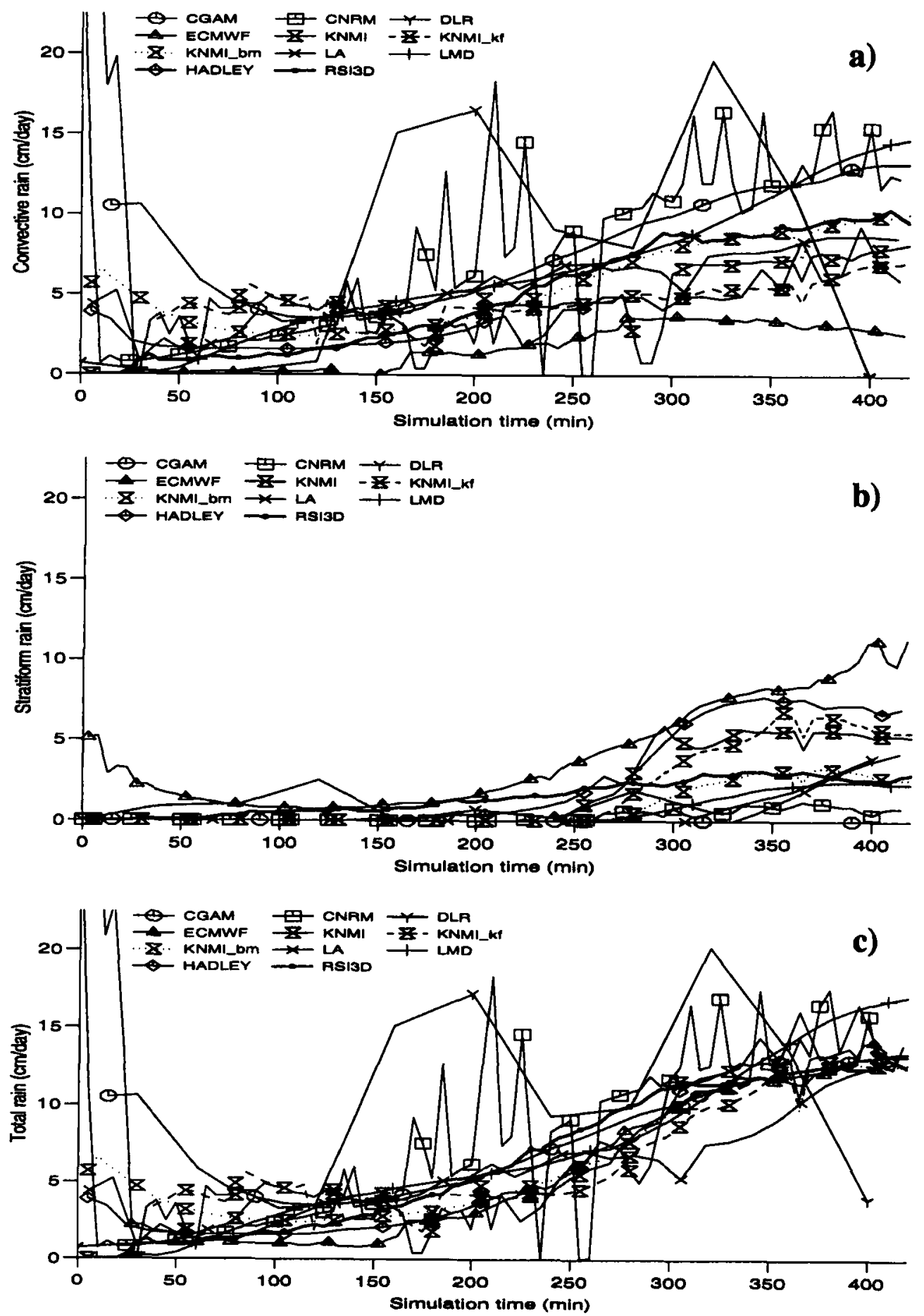

Figure 2. Time series of (a) the surface convective precipitation rate, (b) the surface stratiform precipitation rate and $(c)$ the total precipitation for simulations by different single-column models (see Tables 1 and 2 for explanations of the acronyms). 

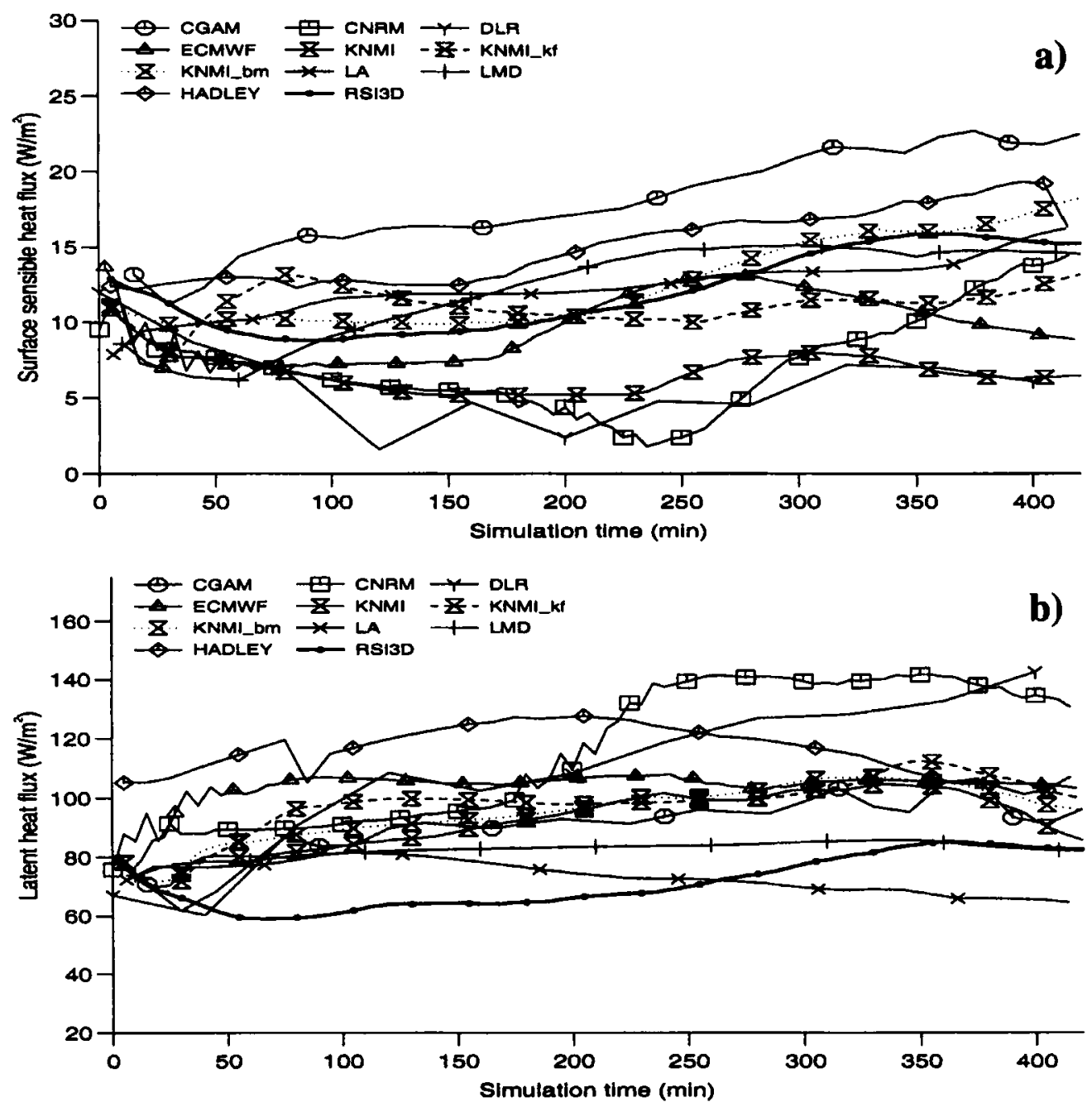

Figure 3. As Fig. 2, but for the surface fluxes of (a) the sensible heat and (b) the latent heat.

condensate storage rates. We conclude from the discussion of the surface precipitation rates that the partitioning between convective and stratiform precipitation is a useful criterion for distinguishing between convection schemes or SCMs. In accordance with suggestions by Emanuel (1997), the total surface precipitation rate seems not to be a decisive criterion in 1D convection tests (provided that the SCMs are able to initiate rain correctly)

Finally, in Fig. 3 we have also illustrated the time evolution of the surface fluxes of sensible and latent heat. All models approximately reproduced the reference CRM results, independently of the way that the models treated the effects of moist unsaturated downdraughts. The maximum deviations from the reference simulation attained $10 \mathrm{~W} \mathrm{~m}^{-2}$ for the sensible-heat flux and $40 \mathrm{~W} \mathrm{~m}^{-2}$ for the latent-heat flux. Such differences might have important consequences in long 3D integrations of a GCM (depending on the interaction with the 'large-scale' flow). However, simple scaling shows that the total surface heat fiux of $120 \mathrm{~W} \mathrm{~m}^{-2}$ (corresponding to a heating of the total atmospheric 
column of about $1 \mathrm{~K} \mathrm{day}^{-1}$ ) is, in the present case, an order of magnitude smaller than the heating equivalent to the surface precipitation/forcing. The column-averaged radiative cooling (not shown here) amounted to $2 \mathrm{~K} \mathrm{day}^{-1}$. Therefore, it is the latent heating that is the primary energy source for the system which is processing moist unstable air.

In the following subsections we concentrate on a discussion of the vertical profiles. Because the squall-line system reached a quasi-stationary state between hour 5 and 7 (Fig. 1), we have only illustrated the vertical profiles representating time averages over the last hour of simulation.

\section{(b) Apparent sources/sinks and mass fluxes}

Traditionally, evaluations of convection schemes have included a comparison of the apparent heat sources and moisture sinks with the observed values. The profiles of $Q_{1 \mathrm{C}}$ and $Q_{2}$, as defined in Eqs. (4) and (6) but normalized by each model's total surface rainfall, are depicted in Fig. 4. These tendencies might have been produced differently in the models, either by the convection scheme and/or by the stratiform cloud scheme. The models reproduced the heating maximum at $8 \mathrm{~km}$ (Fig. 4(a)) and the double structure of the drying profile (Fig. 4(b)). The LA model was also able to reproduce the cooling between 13 and $15 \mathrm{~km}$ due to overshooting convective clouds (Fig. 4(a)). More generally we observe that the SCMs underestimated $Q_{1}$ between 7 and $12 \mathrm{~km}$. At the melting level around $4 \mathrm{~km}$, systematic differences between the SCM values and the reference values existed for both $Q_{1}$ and $Q_{2}$. The consequences of the differences in the $Q_{1}, Q_{2}$ profiles are discussed later in this section and are quantified in terms of temperature and humidity differences.

An alternative way of evaluating convection parametrizations is to compare the convective mass fluxes. Considering the horizontally averaged budget equation for a conserved variable $\Psi$ (e.g. a passive tracer or the equivalent potential temperature neglecting radiation effects)

$$
\frac{\partial \bar{\Psi}}{\partial t}=-\frac{\partial}{\partial z} \overline{w^{\prime} \Psi^{\prime}}+\left.\frac{\partial \Psi}{\partial t}\right|_{\mathrm{frc}}
$$

the 'turbulent' vertical transport term can be expressed using a mass-flux approximation as

$$
\begin{aligned}
\frac{\partial}{\partial z} \overline{w^{\prime} \Psi^{\prime}} \approx & \frac{1}{\bar{\rho}} \frac{\partial}{\partial z}\left[\left(M^{\mathrm{u}}-\bar{M}\right)\left(\Psi^{\mathrm{u}}-\bar{\Psi}\right)+\left(M^{\mathrm{d}}-\bar{M}\right)\left(\Psi^{\mathrm{d}}-\bar{\Psi}\right)\right. \\
& +(\tilde{M}-\bar{M})(\tilde{\Psi}-\bar{\Psi})] \\
\approx & \frac{1}{\bar{\rho}} \frac{\partial}{\partial z}\left[M^{\mathrm{u}} \Psi^{\mathrm{u}}+M^{\mathrm{d}} \Psi^{\mathrm{d}}-\left(M^{\mathrm{u}}+M^{\mathrm{d}}\right) \bar{\Psi}\right]
\end{aligned}
$$

where $M$ denotes the mass flux in $\mathrm{kg} \mathrm{m}^{-2} \mathrm{~s}^{-1}$, the convective up- and downdraught values are denoted by the superscripts ' $u$ ' and ' $d$ ' , respectively, and environmental values are denoted by a tilde. Finally, using the standard mass-flux notation (where the vertical variation of the mass flux is given by mass entrainment $\epsilon$ and detrainment $\delta$ ), we can further expand Eq. (9) to

$$
\frac{\partial}{\partial z} \overline{w^{\prime} \Psi^{\prime}} \approx-\frac{1}{\bar{\rho}}\left[\left(M^{\mathrm{u}}+M^{\mathrm{d}}\right) \frac{\partial \bar{\Psi}}{\partial z}+\delta^{\mathrm{u}}\left(\Psi^{\mathrm{u}}-\bar{\Psi}\right)+\delta^{\mathrm{d}}\left(\Psi^{\mathrm{d}}-\bar{\Psi}\right)\right] .
$$

Therefore, apart from regions with strong detrainment (e.g. close to cloud top) the tendencies are directly proportional to the convective mass flux. 

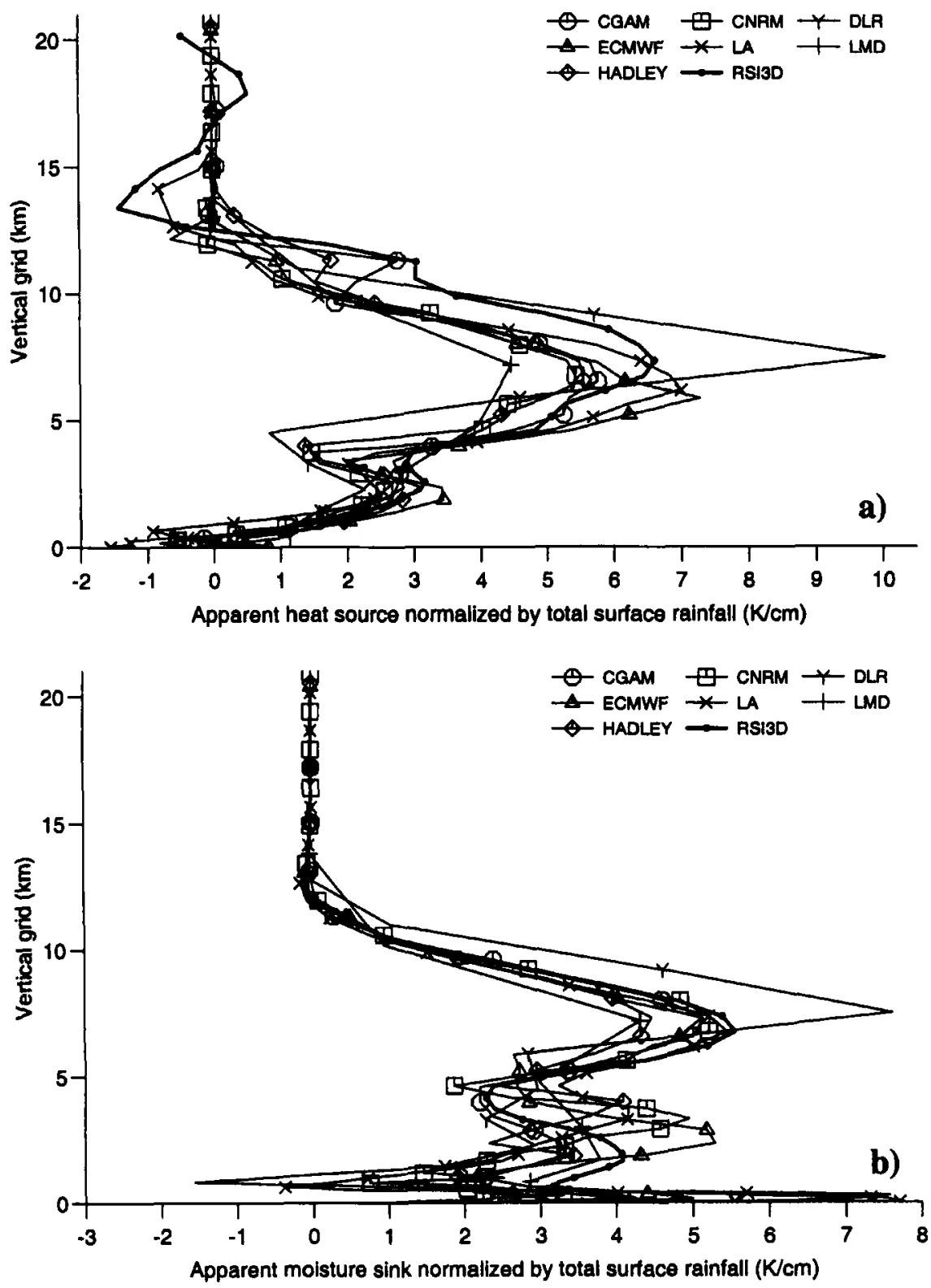

Figure 4. Vertical profiles of (a) the apparent heat source $Q_{1 \mathrm{C}}$ and (b) the moisture sink $Q_{2}$, averaged over hour 7 for simulations by different single-column models (see Tables 1 and 2 for explanations of the acronyms). The quantities have been normalized by the total surface precipitation.

The convective up- and downdraught mass fluxes (not available from all models), as well as the total convective mass flux, are illustrated in Fig. 5. One notes that most models tended to underestimate the magnitude of the convective updraught mass flux in the mid-troposphere by about $30 \%$, but this fact might be due to the criterion used to define the convective updraught/downdraught mass fluxes in the reference CRM. 

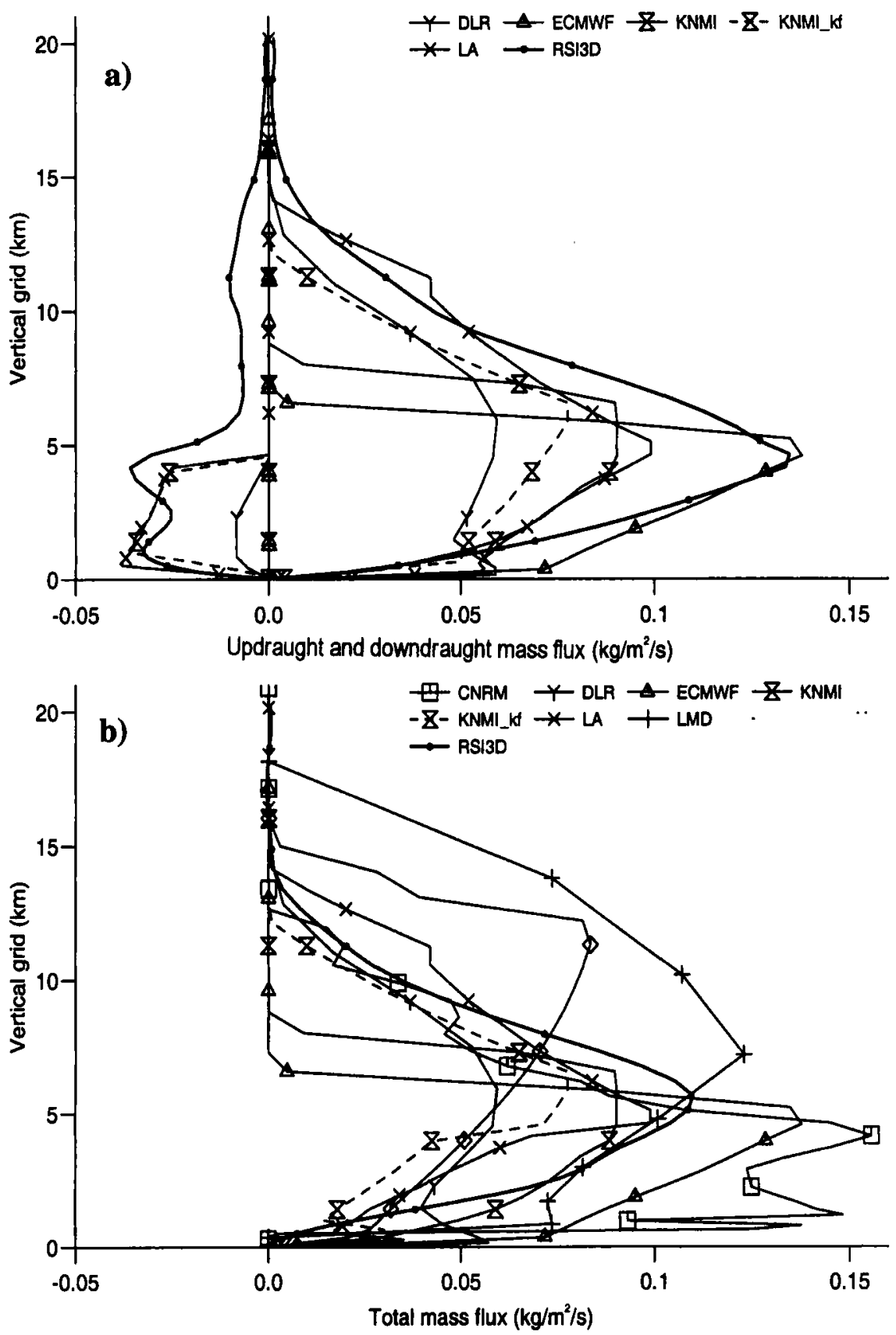

Figure 5. Profiles of (a) the convective updraught/downdraught mass flux and (b) the total mass flux for simulations by different single-column models (see Tables 1 and 2 for explanations of the acronyms). 
ECMWF correctly reproduced the maximum value but underestimated the vertical extension (Fig. 5(a)). The vertical extension of the updraught mass flux is strongly dependent on entrainment, as entrainment reduces the buoyancy and, therefore, reduces the vertical extension of the cloud. The downdraught mass-flux profile was well represented by KNMI_kf and LA; also the downdraught top level at $4.5 \mathrm{~km}$, corresponding to the departure level of a free-sinking parcel that is cooled by evaporation and melting, is well represented by these models. The other models only produced very weak downdraughts. More model results were available for the total convective mass flux. Here we recognize that the models roughly reproduced the reference values, but CNRM and ECMWF overestimated the total mass flux at low levels because the corresponding downdraught mass flux was too weak or not represented. LMD and LA produced a quasi-symmetric profile, but LMD and HADLEY overestimated the mass flux at high levels. The different mass-flux profiles clearly reflect the difficulty in computing correct entrainment rates in mass-flux convection parametrizations. Finally, we point out that the vertical integral of the total convective mass flux is closely related to the surface convective precipitation through an equation similar to Eq. (10), neglecting the detrainment terms:

$$
\begin{aligned}
\operatorname{Pr}=-\int_{0}^{\mathrm{top}}\left[\frac{\partial \bar{q}_{\mathrm{t}}}{\partial t}-\left.\frac{\partial q_{\mathrm{t}}}{\partial t}\right|_{\mathrm{frc}}\right] \mathrm{d} z & \approx \int_{0}^{\mathrm{top}} Q_{2} / L_{\mathrm{v}} \mathrm{d} z \\
& \approx-\int_{0}^{\mathrm{top}} \frac{1}{\bar{\rho}}\left(M^{\mathrm{u}}+M^{\mathrm{d}}\right) \frac{\partial \bar{q}_{\mathrm{t}}}{\partial z} \mathrm{~d} z
\end{aligned}
$$

where $\operatorname{Pr}$ is the precipitation rate and $q_{\mathrm{t}}$ the total (vapour + condensate) moisture content. As a consequence, we observe that the models that best represented the convective mass flux in Fig. 5(b) also reproduced most faithfully the final convective precipitation rate in Fig. 2(a).

\section{(c) Temperature and moisture differences}

The so-called apparent sources $\left(Q_{1}, Q_{2}\right)$ do not provide a clear quantitative evaluation of models or convection schemes. What we are really interested in is the evolution of the model state variables, which are determined by the time-integrated tendencies resulting from small differences between the forcing tendencies and the modelled apparent sources (see Eqs. (3) and (5)). Therefore, we have depicted in Fig. 6 the temperature and moisture differences of the different SCM runs with respect to the reference CRM run. Prior to this analysis, all the SCM results had been interpolated onto the same vertical grid. The differences have only been evaluated for the last hour of the simulation; for the present case this type of analysis is equivalent to plotting the differences with respect to the initial sounding. Concerning the temperature deviations (Fig. 6(a)) we observe that most models produced a negative temperature deviation having maxima at about $5 \mathrm{~km}$ (corresponding to the melting level) and at about $10 \mathrm{~km}$ (corresponding to the level where the cloud-ice concentrations are a maximum). Nevertheless, some models (LA, KNMI, KNMI_kf, LMD) produced quite reasonable results with temperature deviations that were less than $1.5 \mathrm{~K}$ over the whole troposphere (note that the actual heating rates were of order $100 \mathrm{~K} \mathrm{day}^{-1}$ ). However, in contrast to the other models, CNRM and DLR produced positive temperature deviations in the lower and middle troposphere, whereas CGAM and KNMI_bm produced positive temperature deviations of about $3 \mathrm{~K}$ in the middle and upper troposphere. Note that CGAM and KNMI_bm (both using the BettsMiller scheme, but with different adjustment time-scales) produced larger temperature deviations in spite of successful simulations of the convective and stratiform precipitation (Fig. 2). The reason for the larger temperature deviations in CGAM and KNMI_bm 

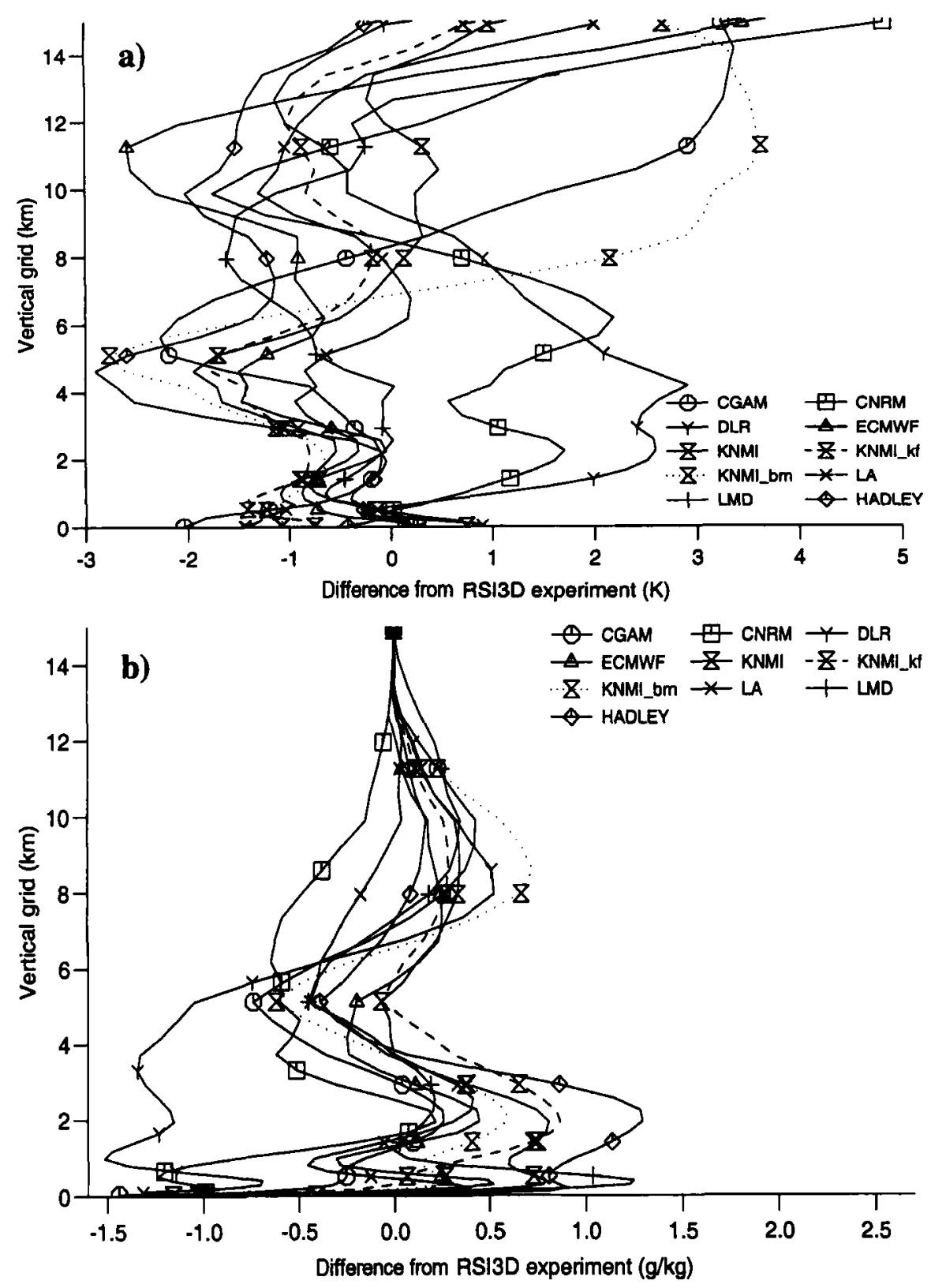

Figure 6. Vertical profiles at hour 7 of the differences between simulations by the reference cloud-resolving model (RSI3D) and by different single-column models (see Tables 1 and 2 for explanations of the acronyms) for (a) the temperature and (b) the specific humidity.

were the temperature lapse rate that was specified and the too dry reference profile. The large spread in the model results above $14 \mathrm{~km}$ was due to the fact that the SCMs generally simulated maximum convective cloud-top heights of about $14 \mathrm{~km}$ and could not counterbalance the temperature forcing (warming) between 14 and $17 \mathrm{~km}$ (Fig. 1).

In contrast to the temperature differences, the profiles of the specific humidity differences (Fig. 6(b)) had similar structures (apart from DLR), with maximum positive 


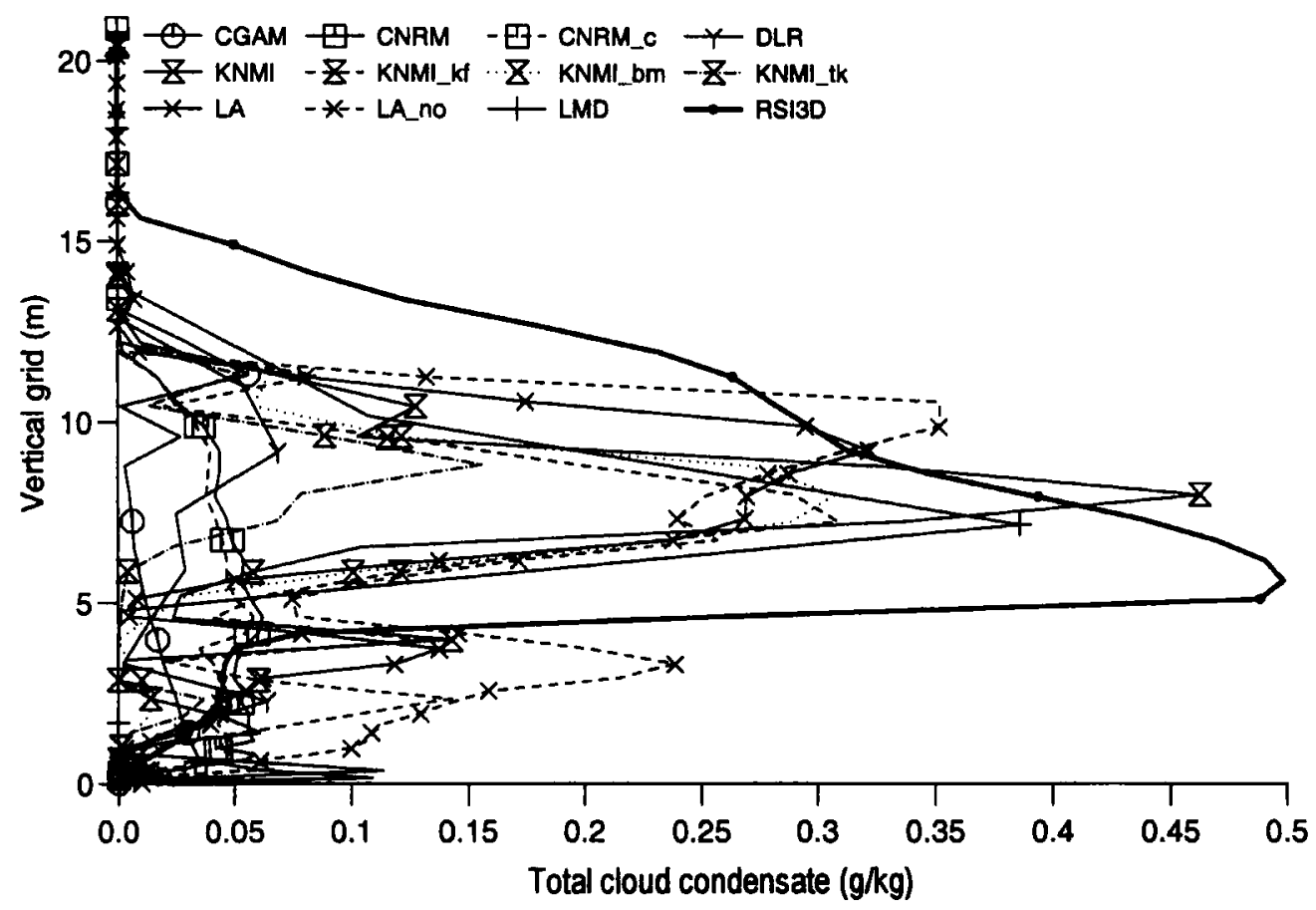

Figure 7. Vertical profiles of the total cloud condensate (liquid + solid) for simulations by different singlecolumn models (see Tables 1 and 2 for explanations of the acronyms).

deviations of about $0.5 \mathrm{~g} \mathrm{~kg}^{-1}$ at about $2 \mathrm{~km}$, and negative deviations at $1 \mathrm{~km}$ and at the melting level at about $5 \mathrm{~km}$.

Finally, we compare in Fig. 7 the profiles of total cloud condensate (liquid + solid). Large differences existed between the SCMs and the reference CRM. In general the SCMs underestimated the vertically integrated condensate content and overestimated the height at which the maximum concentration occurred. As recently outlined by Stephens et al. (1998), such differences might lead to substantial temperature errors in long time integrations through interaction with the radiation scheme.

\section{(d) Sensitivity and no-convection experiments}

As listed in Table 2, some modelling groups also undertook sensitivity experiments with respect to the convective closure. CNRM, ECMWF and KNMI provided simulations using both a CAPE and a moisture-convergence closure. In addition to this, ECMWF provided an experiment (ECMWF_t15) in which the convection routine was called only every $15 \mathrm{~min}$ (as in the operational 3D T213 version of the model) instead of $5 \mathrm{~min}$ (as in the standard SCM run here). Furthermore, LA provided a simulation without a convection scheme labeled LA_no, where only the stratiform cloud scheme was active, in order to assess the impact of a convection parametrization on forced SCM runs.

The time series of the surface convective precipitation for the sensitivity experiments, and the total surface precipitation for the no-convection experiment, are plotted in Fig. 8. We observe in Fig. 8(a) that the use of a CAPE closure (CNRM_c, ECMWF, KNMI) reduced the initial spin-up and significantly smoothed the time evolution of the convective precipitation with respect to a moisture convergence closure (CNRM, 

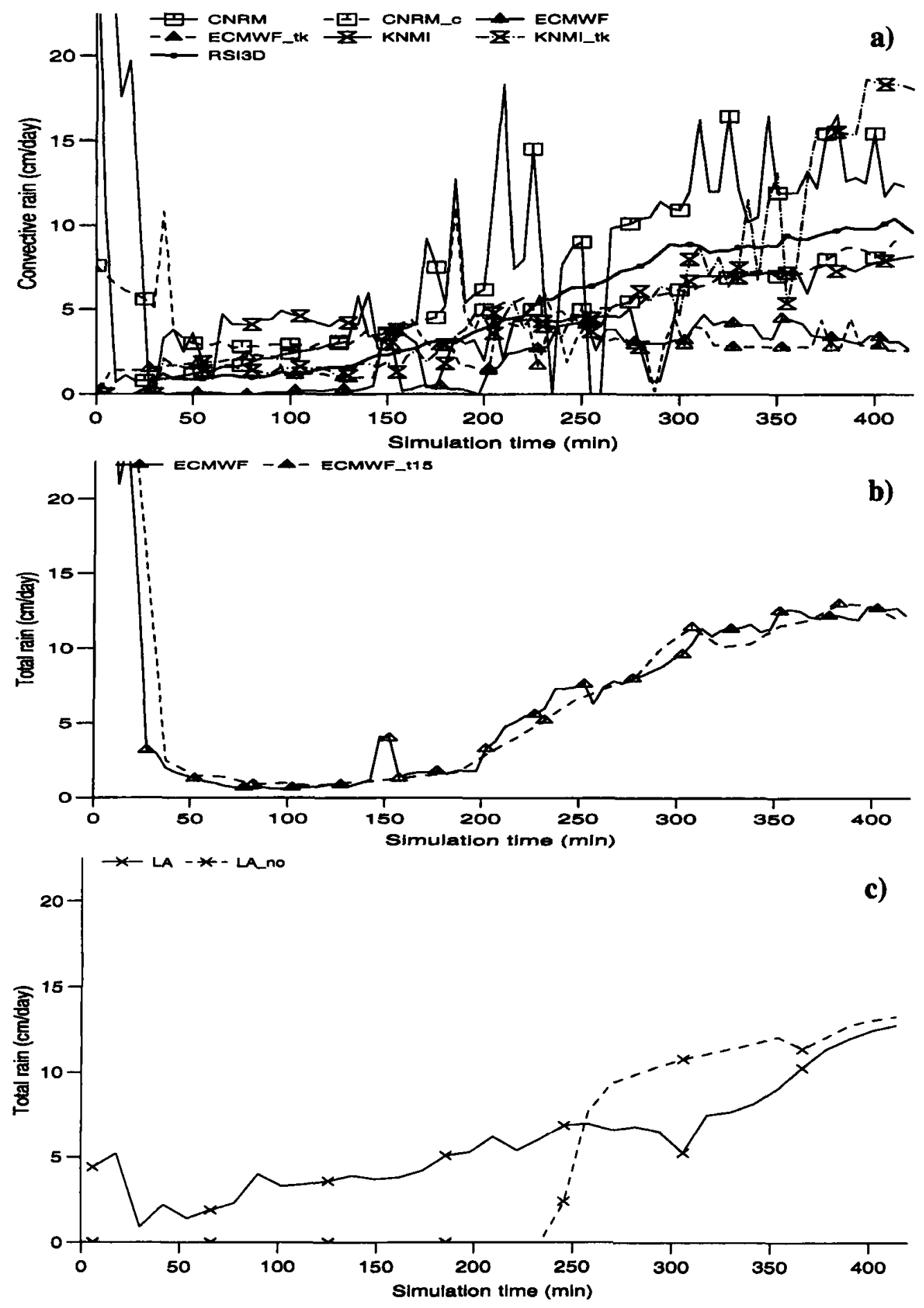

Figure 8. The time series of the convective surface precipitation for (a) the 'convective closure' experiments and (b) the 'time step' experiment. (c) The time series of the total surface precipitation rate for the 'no-convection' experiment. 
ECMWF_tk, KNMI_tk). This result is to be expected as the CAPE closure makes use of a convective time-scale of typically one hour. Instead, the convective equilibrium using a moisture-convergence closure (moisture-tendency closure in the SCMs) is more subtle because moisture convergence as used to drive convection also strongly interacts with the convective activity. The sensitivity experiment with respect to the frequency of the call of the convection scheme (Fig. 8(b)) reveals that the time evolution of the simulated convective rainfall was only a little sensitive to whether the convection scheme was called every $5 \mathrm{~min}$ or every $15 \mathrm{~min}$. Nevertheless, the SCM results were degraded when the time interval between calls of the convection was more than 30 minutes (not shown). However, this is not necessarily true in 3D GCMs or forecast models where the environment responds to the convective forcing by compensating motions, and the final accumulated precipitation or thermodynamic profiles are less sensitive to the frequency with which the convection routine is called. Concerning the total precipitation rate simulated by LA with and without a convection parametrization (Fig. 8(c)), we note that in the convection run precipitation was initiated earlier, but that the total final precipitation rate was identical in both runs. This underlines the statement in the previous section that total precipitation is not a pertinent parameter for evaluating convection parametrizations, at least in cases where the moisture profile of the convective environment is close to saturation.

Finally, we present in Fig. 9 the temperature and moisture differences for the sensitivity and no-convection experiments. In contrast to Fig. 8(a), no significant improvements could be observed for the CAPE closure simulations of CNRM and KNMI compared with simulations using the moisture convergence scheme. This fact indicates that other details of the convection scheme, or even details of the stratiform cloud scheme, are also important. To a minor extent the situation was similar for the no-convection experiment concerning the temperature differences (Fig. 9(b)). The differences in temperature from those in the reference CRM simulation attained about $1 \mathrm{~K}$ in the standard LA convection run, and about $2.5 \mathrm{~K}$ in the corresponding no-convection run. Apart from the lowest $2 \mathrm{~km}$, where downdraught effects are important, both profiles had a similar shape, indicating that there were some basic differences from the reference CRM simulation (microphysics, neglect of mesoscale transport in the stratiform region) that could not be corrected by the use of a convection parametrization alone. However, the situation was different for the profiles of the moisture differences (Fig. 9(d)). Here the convection scheme efficiently transported moisture upward. This could not be achieved in the noconvection run leading to a too moist lower troposphere and a too dry middle and upper troposphere. For an explanation of these facts we follow Guichard et al. (1997) who showed experimentally that the budget equation for temperature (Eq. (4)) is dominated by the term representing the net latent-heat release, whereas in the budget equation for moisture (Eq. (6)) the 'turbulent' transport term and the net condensation term may be equally important.

\section{(e) Forcing strategy and observed bias}

In the previous sections we have only briefly discussed the main differences in the final thermodynamic state between the SCMs and the reference CRM. These differences were partly due to the initial spin-up present in the SCMs, but we also observed that the differences had a rather similar structure for most of the SCMs and that they were also clearly present in a 'no-convection' experiment that did not have any spin-up. The reasons for these differences are now further investigated. The forcing tendencies (Eq. (1)) are proportional to the domain-averaged (total) mass flux. In Fig. 10(a) we have depicted the total mass flux computed from the CRM and its convective contribution for 

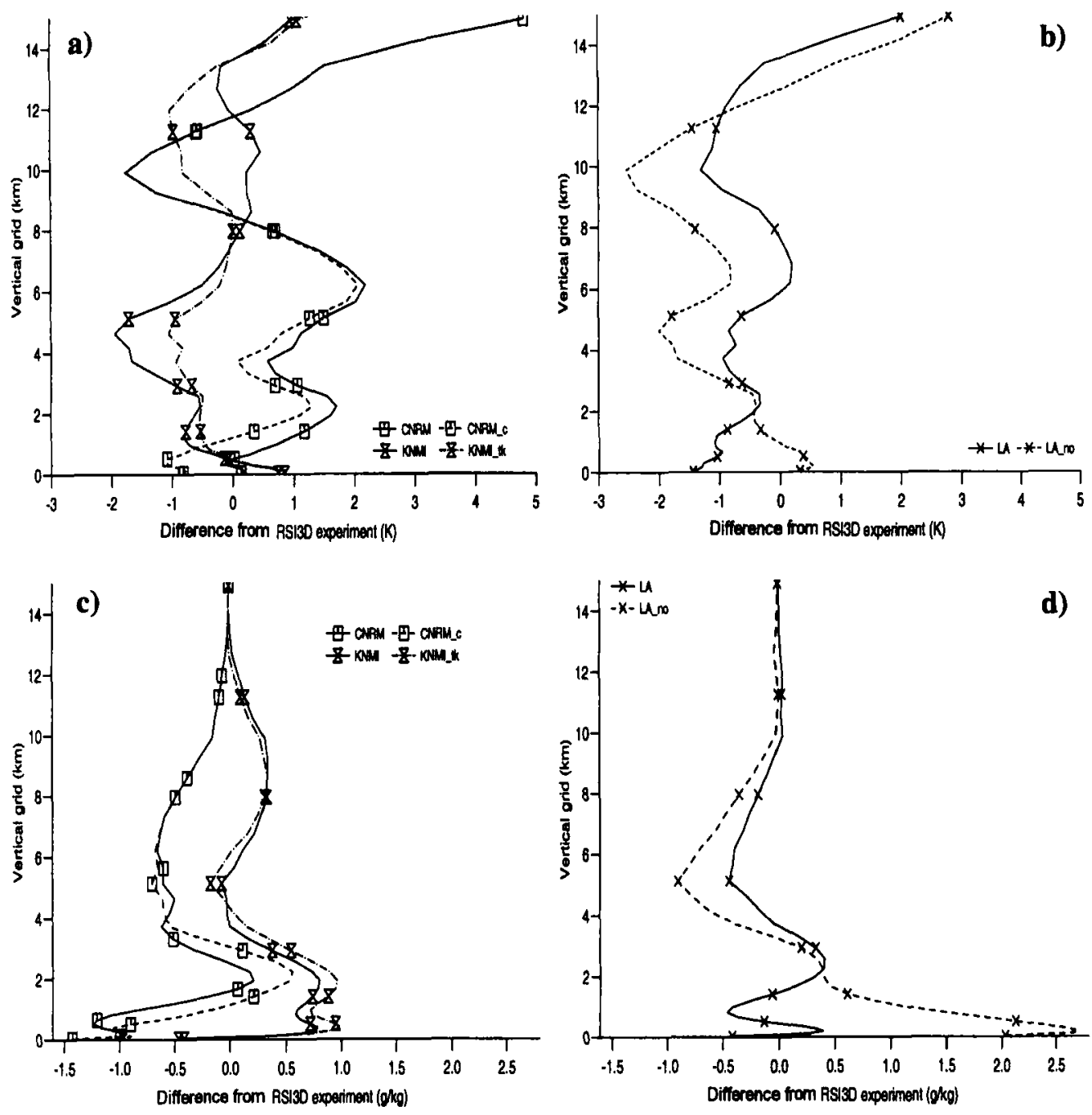

Figure 9. Vertical profiles at hour 7 of the differences between simulations by different single-column models (see Tables 1 and 2 for explanations of the acronyms) and the reference cloud-resolving model (RSI3D) for (a) the temperature and (c) the moisture in the 'sensitivity' experiments, and for (b) the temperature and (d) the moisture in the 'no-convection' experiments.

hour 7 . In contrast to the convective mass flux that has a typical parabolic shape, the total (convective + stratiform) mass flux exhibited two maxima owing to a mesoscale ascent-over-descent circulation couple in the stratiform region. This is a well-known feature and the distinct convective and stratiform contributions to the total mass flux are sometimes referred to as 'mode 1' and 'mode 2', respectively (see Betts 1997; Mapes 1997).

The question that now arises is: provided that the SCMs correctly represent the convective mass flux, are they also able to represent the heating/cooling couplet associated with the stratiform contribution to the mass flux? To a first approximation we can say that convection schemes can only handle the convective contribution to the mass flux (the convective overturning of the conditionally unstable atmosphere); the stratiform (mesoscale) contribution can lead to an additional destabilization of the atmosphere that 

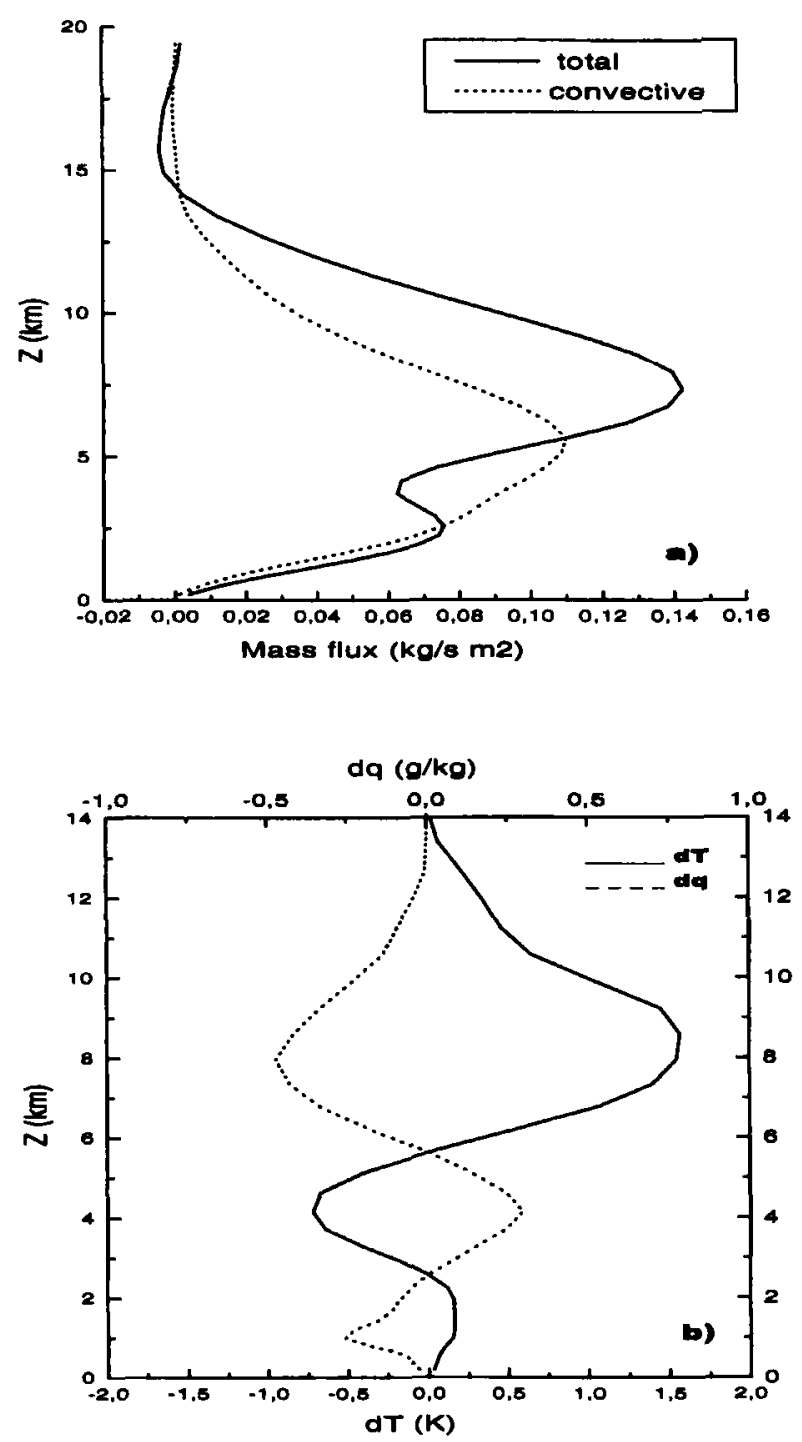

Figure 10. Vertical profiles at hour 7 of the simulation by the reference cloud-resolving model (RSI3D) of (a) the total and convective mass flux and (b) the one-hour temperature and moisture tendencies.

a convection scheme might partly account for. Therefore, it is straightforward to assume that, to a first approximation, the neglect of the stratiform contribution to the mass flux is responsible for the observed temperature and moisture differences in Fig. 6. The temperature and moisture tendencies associated with the stratiform mass-flux contribution can be estimated with the aid of Eqs. (8) and (10) using the mass-flux values given in Fig. 10(a) and the initial sounding for $\theta$ and $q_{\mathrm{v}}$, i.e. $\Delta Q_{1} / C_{p} \approx \bar{\Pi} \bar{\rho}^{-1} \Delta M \partial \bar{\theta} / \partial z$, and $\Delta Q_{2} / L_{\mathrm{v}} \approx-\bar{\rho}^{-1} \Delta M \partial \bar{q}_{\mathrm{v}} / \partial z$, with $\Delta M$ the stratiform contribution to the mass flux. In Fig. 10(b) we have plotted the corresponding temperature and moisture tendencies integrated over one hour. For the moisture-difference profile we clearly retrieve the negative-positive-negative bias structure that is evident in the SCM runs. Figure $10(\mathrm{~b})$ is coherent, with the differences observed in the $Q_{2}$ profiles at hour 7 (Fig. 4(b)), but there 
is a slight vertical shift with respect to the final moisture-difference profiles observed in Figs. 8(d) and 6(b).

Concerning the temperature tendency profile, we recognize that Fig. 10(b) explains the negative temperature bias at $5 \mathrm{~km}$ as well as the local minimum at $8 \mathrm{~km}$ observed in Figs. 6(a) and 9(a). Nevertheless, Fig. 10(b) cannot explain the negative temperature bias of the SCMs above $8 \mathrm{~km}$, suggesting that microphysical transformations and the interaction with the radiation are responsible for this feature. The fundamental difference between the forced SCM runs and the reference CRM run is related to the fact that the SCMs became completely saturated throughout most of the troposphere, whereas in the CRM only half of the horizontal domain was filled by clouds (Part I, Fig. 7). This necessarily raises the question of whether forced SCM runs can produce results equivalent to 3D CRM runs. This question can only be answered by running additional CRM simulations with open boundary conditions and applying the same forcing as in the SCMs. To our knowledge this exercise has not yet been done, because of the inherent technical difficulties.

\section{CONCLUSIONS}

Eight SCMs have been compared with a reference CRM simulation for an intense tropical squall-line case observed during TOGA-COARE. The method employed to force the SCMs is original as it uses tendencies computed from the domainaveraged CRM fields. Our objective was to evaluate 'state-of-the-art' deep convection parametrizations and their interaction with the 'resolved' (stratiform) cloud physics. The present squall-line case was particularly attractive because about $70 \%$ of the total precipitation occurred as convective precipitation and $30 \%$ as stratiform precipitation.

It was shown that SCMs are able to reproduce reasonably well the time evolution of the surface convective and stratiform precipitation in addition to the temperature and moisture structure of the squall-line system. Bulk mass-flux convection schemes still have difficulties in representing the shape of the mass-flux profiles, even if some schemes were capable of closely representing the mass flux associated with moist unsaturated downdraughts. However, structural differences persisted in the thermodynamic profiles simulated by the SCMs and the CRM. These structural differences could be attributed to the fact that the total mass flux used to compute the SCM forcing was different from the convective mass flux. The SCMs could not adequately represent the organized mesoscale circulations and microphysical/radiative forcing associated with the stratiform region. This issue is generally known as the 'scale-interaction' problem that can only be properly addressed in fully 3D simulations.

Convection schemes should be considered as complete entities, and it is difficult to concentrate on only some aspects of a scheme. Nevertheless, sensitivity experiments for the present case have confirmed that the use of a convective closure based on the convective available potential energy is preferable to one based on the convergence of moisture, as it leads to a smoother evolution of the surface convective precipitation and reduces the initial model spin-up.

Concerning the method of evaluating convection schemes in SCM mode, we recommend running the SCM (i.e. calling the convection routine) with a time step less than, say, 15 min. Furthermore, our results suggest that the total surface precipitation, as well as the so-called apparent sources, are not reliable measures of the quality of a convection parametrization. Instead, one should consider as valid measures the partitioning between convective and stratiform precipitation, the convective mass flux and the temperature and moisture structures. Passive tracers might also be considered as useful quantities. 
Finally, in order to assess the impact of a convection parametrization on forced SCM runs, we recommend performing additional 'no-convective' simulations where only the stratiform cloud scheme is active. An alternative way of assessing this impact would be to run a CRM with open boundary conditions and apply the same forcing as in the SCMs. Because of technical difficulties, this latter approach has not yet been tested.

The GCSS working group on 'Precipitating Convective Cloud Systems' has just started its model intercomparison project. The present test case has already helped in detecting and correcting some errors and deficiencies in several convection schemes. Future test cases will include long time integrations with emphasis on cloud-radiation interactions, and also cases of continental convection. Our hope is that the present case might serve as a well-defined and easy to perform test case for convection modellers.

\section{ACKNOWLEDGEMENTS}

We would like to express our gratitude to Drs John Mitchell, Mitch Moncrieff and Steve Krueger, who led the GCSS Precipitating Convective Clouds Working Group. We have also greatly profited from comments by two anonymous reviewers. The first author acknowledges the help of E. van Meijgaard and the group of A. A. M. Holtslag and A. van Ulden during his stay at KNMI. Funding for this work was provided by many sources, including grants from the European Commission (the EUCREM project) (S. Brinkop, F. Guichard and E. Ioannidou), program PATOM/INSU (P. Bechtold), and the UK Natural Environment Research Council (M. Blackburn).

\section{REFERENCES}

Alexander, G. D., and Cotton, W. R. 1998

Arakawa, A. and Schubert, W. H.

1974

Bechtold, P.

Bélair, S., Zhang, D.-L. and Mailhot, J.

Betts, A. K.

Betts, A. K. and Miller, M. J.

Blackadar, A. K.
Bougeault, P.
Chao, C. W. and Deng, L.
Cuxart, J., Bougeault, P. and
Redelsperger, J.-L.
Davis, C. A., Stoelinga, M. T. and
Kuo, Y-H.
Emanuel, K. A.

1979

1985

1998

2000

1993

1991
The use of cloud resolving simulations of mesoscale convective systems to build a mesoscale parameterization scheme. J. Atmos. Sci., 55, 2137-2161

Interaction of a cumulus cloud ensemble with the large-scale environment. Part I. J. Atmos. Sci., 31, 674-701

'The Meso-NH convection scheme'. Technical Memorandum (available from Meteo France/CNRM, av. Coriolis, 31057 Toulouse Cedex, France)

Numerical prediction of the 10-11 June 1985 squall line with the Canadian regional finite-element model. Weather Forecasting, 9, 157-172

'The parameterization of deep convection'. Pp. 255-279 in The physics and parameterization of moist atmospheric convection, Ed. R. K. Smith, NATO ASI Series, 505

A new convective adjustment scheme. II: Single column tests using GATE-wave, BOMEX, ATEX, and Arctic Airmass data sets. Q. J. R. Meteorol. Soc., 112, 677-692

'The Betts-Miller scheme'. Pp. 107-121 in The representation of cumulus convection in numerical models, Eds. K. A. Emanuel and D. J. Raymond, Meteorol. Monographs, 24

High-resolution models of the planetary boundary layer. $A d v$. Environ. Sci. Eng., 1, 50-85

A simple parameterization of the large-scale effects of cumulus convection. Mon. Weather Rev., 113, 2108-2121

Tropical intraseasonal oscillation, super cloud clusters, and cumulus convection schemes. Part II: 3D aquaplanet simulations. J. Atmos. Sci., 55, 690-709

A turbulence scheme allowing for mesoscale and large-eddy simulations. Q. J. R. Meteorol. Soc., 126, 1-30

The integrated effect of condensation in numerical simulations of extratropical cyclogenesis. Mon. Weather Rev., 121, 23092330.

A scheme for representing cumulus convection in large-scale models. J. Atmos. Sci., 48, 2313-2335 
Emanuel, K. A.

1997

Fritsch, J. M., Houze, R. A., Adler, R., Bluestein, $\mathrm{H}$., Bosart, L., Brown, J., Carr, F., Davies, C., Johnson, R. H, Junker, N., Kuo, Y.-H., Rutledge, S., Smith, J., Toth, Z., Wilson J. W., Zipser, E. and Zrnic, D.

Gregory, D. and Rowntree, P. R.

Gregory, D., Morcrette, J. J., Jakob, C. and Beljaars, A. C. M.

Grell, G. A.

Guichard, F., Redelsperger, J.-L. and Lafore, J. P.

Holtslag, A. A. M. and Boville, B. A.

Inness, P. M. and Gregory, D.

Kain, J. S. and Fritsch, J. M.

Louis, J. F.

Mapes, B. E.

Moncrieff, M. W., Gregory, D., Krueger, S. K., Redelsperger, J.-L. and Tao, W. K.

Morcrette, J.-J.

Nordeng, T. E.

Raymond, D. J.

Redelsperger, J.-L., Brown, P. R. A., Guichard, F., Hoff, C., Kawasima, M., Lang, S., Montmerle, T., Nakamura, K., Saito, K., Seman, C., Tao, W. K. and Donner, L. J.

Ritter, B. and Geleyn, J.-F.

1998

1998

1992
'The problem of convective moistening'. Pp. 255-279 in The physics and parameterization of moist atmospheric convection, Ed. R. K. Smith, NATO ASI Series, 505

Quantitative precipitating forecasting: Report of the eighth prospectus development team, US weather research program. Bull. Amer. Meteorol. Soc., 79, 285-299

A mass-flux convection scheme with representation of cloud ensemble characteristics and stability dependent closure. Mon. Weather Rev., 118, 1483-1506

'Introduction of revised radiation, convection, cloud and vertical diffusion schemes into Cy18r3 of the ECMWF Integrated Forecasting System'. ECMWF Research Department Technical Note (available from ECMWF, Shinfield Park, Reading RG2 9AX, UK)

1993 Prognostic evaluation of assumptions used by cumulus parameterizations. Mon. Weather Rev., 121, 764-787

1997 Thermodynamical impact and internal structure of a tropical convective cloud system. Q. J. R. Meteorol. Soc., 123, 22972324

1993 Local versus nonlocal boundary-layer diffusion in a global climate model. J. Climate, 6, 1825-1842

1997 Aspects of the intraseasonal oscillation simulated by the Hadley Centre atmospheric model. Climate Dyn., 13, 441-458

1993 'Convective parameterization for mesoscale models: The KainFritsch scheme'. Pp. 165-170 in The representation of $\mathrm{cu}$ mulus convection in numerical models, Eds. K. A. Emanuel and D. J. Raymond, Meteorol. Monographs, 24

1979 A parametric model of vertical eddy fluxes in the atmosphere. Boundary-Layer Meteorol., 17, 187-202

1997 'Equilibrium versus activation control of large-scale variations of tropical deep convection'. Pp. 321-358 in The physics and parameterization of moist atmospheric convection, Ed. R. K. Smith, NATO ASI Series, 505

1997 GEWEX Cloud System Study (GCSS) working group 4: Precipitating convective cloud systems. Bull. Amer. Meteorol. Soc., 78, 831-845

1989 Impact of changes to the radiation transfer parameterizations plus cloud optical properties in the ECMWF model. Mon. Weather Rev., 118, 847-873

1994 'Extended versions of the convection parameterization scheme at ECMWF and their impact upon the mean climate and transient activity of the model in the tropics'. ECMWF Technical Memorandum 206 (available from ECMWF, Shinfield Park, Reading RG2 9AX, UK)

'Critical observations of convection-state of the art and a proposal'. Pp. 447-462 in The physics and parameterization of moist atmospheric convection, Ed. R. K. Smith, NATO ASI Series, 505

A GCSS model intercomparison for a tropical squall line observed during TOGA-COARE. I: Cloud-resolving models. Q. J. $R$. Meteorol. Soc., 126, 823-863
A comprehensive radiation scheme for numerical weather prediction models with potential applications in climate simulations. Mon. Weather Rev., 120, 303-325 
Roux, F.

1998

Sénési, S., Bougeault, P., Chèze, J.-L., Cosentino, P. and Thepenier, R.-M.

Short, A. D., Kucera, P. A., Ferrier, B. S., Gerlach, J. C., Rutledge, S. A. and Thiele, $\mathrm{O}$. W.

Slingo, J. M., Blackburn, M., Betts, A. K., Brugge, R., Hodges, K. D., Hoskins, B. J., Miller, M. J.,

Steenman-Clark, L. and Thuburn, J.

Stephens, G. L., Jakob, C. and Miller, $\mathrm{M}$.

Sun, W.-Y. and Haines, P.

Taylor, J. P., Edwards, J. M., Glew, M. D., Hignett, P. and Slingo, A.

Tiedtke, $\mathbf{M}$.

Wang, W. and Seaman, N. L.

Xu, K.-M. and Arakawa, A.

Yano, J.-I., Williams, J. C. and Moncrieff, M. W.

Zhang, D.-L. and Fritsch, J. M.
1996
The oceanic mesoscale convective system observed with airborne Doppler radars on 9 february 1993 during TOGA-COARE: Structure, evolution and budgets: $Q . J$. R. Meteorol. Soc., $124,585-614$

The Vaison-la-Romaine flash flood: Mesoscale analysis and predictability issues. Weather Forecasting, 11, 417-442

Shipboard radar rainfall patterns within the TOGA COARE IFA. Bull. Amer. Meteorol. Soc., 78, 2817-2836

Mean climate and transience in the tropics of the UGAMP GCM: Sensitivity to convective parameterization. Q.J.R. Meteorol. Soc., 120, 881-922

'Atmospheric ice-a major gap in understanding the effects of clouds on climate'. Pp. 1-20 in GEWEX News, 8, Ed. P. F. Twitchell, (available from GEWEX project office)

Semi-prognostic tests of a new cumulus parameterization scheme for mesoscale modelling. Tellus, 48A, 272-289

Studies with a flexible new radiation code. II: Comparisons with aircraft short-wave observations. Q. J.R. Meteorol. Soc., 122, 839-861

A comprehensive mass flux scheme for cumulus parameterization in large-scale models. Mon. Weather Rev., 117, 1779-1800

A comparison study of convective parameterization schemes in a mesoscale model. Mon. Weather Rev., 125, 252-278

Semiprognostic tests of the Arakawa-Schubert cumulus parameterization using simulated data. J. Atmos. Sci., 49, 2421 2436

Fractality in simulations of large-scale tropical cloud systems. Mon. Weather Rev., 124, 838-848

umerical sensitivity experiments of varying model physics on the structure, evolution and dynamics of two mesoscale convective systems. J. Atmos. Sci., 45, 261-292 